\title{
МЕТОДОЛОГИЧЕСКИЕ ПОДХОДЫ К ОЦЕНКЕ ОРГАНИЗАЦИОННО- ПРАВОВОГО ОБЕСПЕЧЕНИЯ ФОРМИРОВАНИЯ ИНВЕСТИЦИОННОГО КЛИМАТА В СФЕРЕ ОБОРОННО-ПРОМЫШЛЕННОГО КОМПЛЕКСА В УСЛОВИЯХ ЦИФРОВОЙ ЭКОНОМИКИ
}

\author{
(c) 2021 Сингилевич Дмитрий Александрович \\ кандидат военных наук, доцент, полковник запаса
}

Руководитель секции правовых проблем обороны государства - заместитель руководителя Экспертного совета Комитета Государственной Думы Российской Федерации по обороне E-mail: dsingilevich@yandex.ru.

В статье рассмотрены возможные методики оценки организационно-правового обеспечения инвестиционного климата формирования в оборонно-промышленном комплексе, сформулированы методологические подходы к оценке организационно-правового обеспечения, предлагается система показателей для оценки организационно-правового обеспечения.

Ключевые слова: организационно-правовое обеспечение, методика оценки, методологические подходы, показатели организационно-правового обеспечения, интегрированные показатели.

Определение зависимости и взаимной обусловленности, а также количественной характеристики между состоянием организационно-правового обеспечения формирования инвестиционного климата в сфере ОПК в условиях цифровой экономики (далее организационно-правовое обеспечение) и эффективностью функционирования обороннопромышленной отрасли представляется одной из важнейших задач, решение которой позволит своевременно выявлять проблемные зоны в области управления инвестиционной деятельностью, определять слабые стороны, раскрывать неявные резервы отрасли и оперативно купировать выявленные проблемы, прогнозировать их возникновение [6, 7, 12]. При этом под эффективностью функционирования обороннопромышленной отрасли будем понимать не только производство высокотехнологичного вооружения в объемах и сроках, необходимых для поддержания боеготовности своих Вооруженных Сил на заданном уровне, но и успешное продвижение своей продукции на внешних рынках.

Существующие в настоящее время методики оценки инвестиционной деятельности позволяют оценить ее эффективность в зависимости от влияния как отдельных, так и комплекса факторов.

В тоже время в части касающейся организационно-правовых аспектов формирования инвестиционного климата в оборонно- промышленном комплексе в условиях цифровой экономики - управленческого, правового и маркетингового - разработка комплексных подходов, позволяющих оценить степень их влияния на качество инвестиционной деятельности в оборонно-промышленной отрасли, ведется с интенсивностью, не представляющей возможности сделать выводы о наличии методологических основ в этой сфере $[3,5,10]$.

Применяемые методы оценки и диагностики позволяют измерить и проанализировать влияние управленческого, правового и маркетингового аспектов по отдельности, но как правило без учета специфики оборонной отрасли, функционирующей в условиях цифровой экономики $[1,2,8]$. Вместе с тем специфика обороннопромышленного комплекса не предполагает шаблонных схем, так как в зависимости от вида производимой продукции, состояния производственных мощностей, возможности экспортирования совокупное влияние организационноправовых аспектов и влияние каждого из них по отдельности будет разным.

Объявление и наложение санкций на российские компании из состава ОПК, постоянное расширение «черного» списка показывает, что руководство США постарается убрать все компании - конкуренты, расчищая международный рынок вооружений для компаний своего военно-промышленного комплекса.

Такое развитие событий на международном рынке вооружений, обусловленное высочайшим 
уровнем конкуренции, предъявляет к компаниям- производителям вооружений, военной (специальной) техники (далее - BB(C)T) - весьма жесткие требования, выполнение которых позволит не только остаться на рынке, но и развиваться и искать новые ниши.

В этих условиях владение оперативной обстановкой, в том числе знание состояния организационно-правового обеспечения формирования инвестиционного климата позволит поддержать уровень инвестирования, сохраняя и развивая производственные мощности, повышая качество производимых $\mathrm{BB}(\mathrm{C}) \mathrm{T}$ и как следствие обеспечит конкурентные преимущества российских компаний.

В методике оценки организационноправового обеспечения формирования инвестиционного климата в сфере ОПК в условиях цифровой экономики представляется необходимым:

- включение цели, задач, объекта оценивания, рассмотрение современных методов оценки организационно-правового обеспечения по отдельности и вместе, обоснование выбора подхода к оценке;

- фиксация изменений содержания механизма оценки согласно целям анализа и свойствам исследуемого объекта;

- представление на основе разработанной методики рассмотрения объекта результатов оценки и самой системы оценки организационно-правового обеспечения, как целостную завершенную систему оценки;

- раскрытие потенциала для последующего совершенствования организационно-правового обеспечения.

Оценка организационно-правового обеспечения формирования инвестиционного климата в сфере ОПК в условиях цифровой экономики позволяющая объективно проанализировать результаты хозяйственной деятельности, представляется основой для планирования и прогнозирования деятельности по привлечению инвестиций, устойчивости оборонной отрасли в конкурентной борьбе как на внутреннем, так и на международных рынках вооружений, формирования имиджа, соответствующего современным требованиям, предъявляемым к предприятиям ОПК $[4,9,11]$.

Таким образом, суть современной оценки организационно-правового обеспечения формирования инвестиционного климата в сфере
ОПК в условиях цифровой экономики должна заключаться в измерении способности предприятий ОПК привлекать необходимый объем инвестиций в условиях жесткой конкуренции, максимально полезно применяя уровень управления, правовую базу и систему маркетинга.

Для оценки организационно-правового обеспечения формирования инвестиционного климата в сфере ОПК в условиях цифровой экономики представляется обоснованным использовать следующие подходы:

- для оценки организационно-правового обеспечения как непростого, разностороннего, многозначного явления, с учетом его развития и перманентной эволюции - диалектический;

- для оценки организационно-правового обеспечения как целостного комплекса взаимосвязанных элементов (управленческих, правовых, маркетинговых), установления характера и способа отношений между ними, а также внутренних коммуникации категорий - системный;

- для оценки организационно-правового обеспечения как постоянно эволюционирующей системы, позволяющей обосновывать его совершенствование результатом срабатывания принципа эмерджентности за счет объединения отдельных элементов в единую систему, как следствие получения системного эффекта - синергетический;

- для оценки влияния на формирование инвестиционного климата в сфере ОПК организационно-правовых аспектов, как многостороннего комплекса формализованных и неформализованных видов совместной деятельности, которые прямо воздействую на устойчивое и эффективное развитие обороннопромышленной отрасли в условиях цифровой экономики - институциональный.

Оценка организационно-правового обеспечения формирования инвестиционного климата в сфере ОПК в условиях цифровой экономики должна включать в себя систему показателей, характеризующих управленческие устойчивость, непрерывность и оперативность, эффективность правовой системы, актуальность и креативность маркетинговых стратегий в условиях цифровой экономики. Показатели выступают датчиками, информирующими о положительном или неблагополучном состоянии исследуемой системы и показывают степень эффективности процессов управления и организации, состояние и разви- 
тие системы правового обеспечения, качество маркетинговой политики, а также степень конкурентоспособности в привлечении инвестиций, и т.д.

Комплексная система показателей по каждому аспекту организационно-правового обеспечения должна стать основой для методики оценки организационно-правового обеспечения, при безусловном соблюдении правила системного единства. Основные требования к процедуре измерения организационно-правового обеспечения позволяют сформулировать итоги исследования методологических подходов, определяющих зависимость и взаимную обусловленность, а также количественную характеристику между состоянием организационно-правового обеспечения формирования инвестиционного климата в сфере ОПК в условиях цифровой экономики и эффективностью функционирования обороннопромышленной отрасли.

1. Оценивать необходимо всю совокупность элементов организационно-правового обеспечения в целом. В соответствии с определенным наполнением организационноправового обеспечения, в его оценки должны содержаться наиболее важные параметры, влияющие на формирование инвестиционного климата и определяемые следующими группами показателей:

а) управленческие:

- качество управленческих кадров,

- устойчивость, непрерывность и оперативность управленческого воздействия;

- качество организации, планирования и контроля инвестиционной деятельности;

б) правовые:

- уровень выполнения правовых норм при осуществлении инвестиционной деятельности;

- эффективность правового обеспечения инвестиционной деятельности;

- своевременность и оперативность внесения изменений в правовые акты

в) маркетинговые:

- взаимосвязь доли рынка и возможностей покупателей $\mathrm{BB}(\mathrm{C}) \mathrm{T}$ - доля рынка, сохранение и расширение базы покупателей, удовлетворение потребностей покупателя, прибыльность покупателя;

- эффективность использования маркетинговых коммуникаций;

- эффективность создания и продвижения на рынке инвесторов привлекательного образа государства (отрасли, экономики в целом).

2. В процессе оценивания в обязательном порядке должен рассчитываться интегральный показатель, объединяющий в группы отдельные показатели организационно-правового обеспечения с их последующим интегрированием.

3. Наряду с субъективным экспертным анализом для соответствия требованиям максимальной объективности, методы оценки организационно-правового обеспечения должны включать и аппарат экономико-математического моделирования, а также обоснование каждого применяемого показателя.

4. Методы оценки организационноправового обеспечения должны быть нацелены на получение максимально достоверных результатов исследования и соответствовать целям формирования инвестиционного климата оборонно-промышленного комплекса в условиях цифровой экономики.

5. В целях повышения качества организационно-правового обеспечения информация, получаемая в результате содействия сформированной системы оценки, должна отвечать требованиям полноты, достоверности и репрезентативности.

Алгоритм комплексной оценки организационно-правового обеспечения формирования инвестиционного климата в сфере ОПК в условиях цифровой экономики должен включать подготовительный, методологический и методический этапы.

На подготовительном этапе определяется цель оценки организационно-правового обеспечения и выбирается объект исследования.

Методологический этап заключается в выборе и обосновании метода оценки организационно-правового обеспечения на основе изучения существующих методических подходов и переформатировании (при необходимости) выбранного метода оценки согласно целям и особенностям изучаемого объекта.

При проведении методического этапа:

- определяются возможности повышения эффективности организационно-правового обеспечения;

- ранжируются корпорации и отдельные предприятия ОПК по состоянию организационно-правового обеспечения формирования инвестиционного климата;

- производится оценка организационно- 
правового обеспечения, включающая в себя процедуры расчета частных, групповых и интегральных показателей;

- проводится сбор и анализ необходимой репрезентативной информации.

Практика показывает, что основным условием получения достоверных результатов оценки организационно-правового обеспечения является наличие квалифицированных специалистов, владеющих методами оценивания, хорошо разбирающихся в источниках информации, спо- собных дать объективную оценку надежности используемой информации и сформулировать необходимые выводы.

По итогам комплексной оценки и последующей группировки предприятий проводится работа по формированию стратегии повышения эффективности организационно-правового обеспечения формирования инвестиционного климата, максимально соответствующая современным условиям деятельности обороннопромышленного комплекса.

\section{Библиографический список}

1. Артемьева, В.С.Сравнительная оценка методических подходов к анализу экономического потенциала предприятия [Текст] / В.С.Артемьева // Экономический анализ: теория и практика.- 2010.- № 36.- С. 22-31.

2. Власенко, О.В. Интегральная оценка динамики экономического потенциала коммерческопредпринимательской структуры и его использования [Текст]: дис. ... канд. экон. наук: 08.00.05 / О.В.Власенко.-Омск, 2006.- 190 с.

3. Голубев С.С., ГорбуноваВ.В., ЕфремовА.А. Методика отбора приоритетных технологий для развития производственно-технологической базы предприятий ОПК России // Научный вестник обороннопромышленного комплекса России. 2019. № 4. С. 24-29

4. Дабиев Д.Ф. О методологии оценки экономического потенциала регионов // Фундаментальные исследования. - 2019. - № 12-2.- С. 258-262.

5. Ефремов А.А., Щербаков В.В. Инвариантность сетевых форм организации логистических цепей // Вестник Астраханского государственного технического университета. Серия: Экономика. 2011. № 2. С. $72-79$

6. Карсунцева, О.В.Методологические подходы к оценке производственного потенциала [Текст] / О.В.Карсунцева // Вестник университета / Гос. ун-т управления. - 2013. - № 5. - С. 126-132.

7. Прохоров Р.E. Международное военное сотрудничество России со странами Южной Азии // Сборник материалов круглого стола «Современный миропорядок и его влияние на национальную безопасность Российской Федерации».- М.: ВАГШ ВС РФ, 2020-611 с.

8. Секерин В.Д.Горохова А.Е. Инновационная среда как фактор эффективности коммерциализации инноваций // Известия Московского государственного технического университета МАМИ. 2014. Т. 5. № 2 (20). С. 39-43

9. Секерин В.Д., ГороховаА.Е., ЛаптеваД.Я., Калинкина Т.М.Научно-техническая информация как фактор развития общества // Известия МГТУ «МАМИ».-2013. № 1 (15), т.5.- С. 136-141

10. Семенова В.В., Шурукова Е.Е., Гасанбеков С. К. Социально-экономическое развитие: социальный стресс и адаптация как технология управления развитием // Финансовая экономика, 2020. - № 7(2). - С. 182-184

11. Чирихин С.Н.Ключевые проблемы формирования благоприятного инвестиционного климата России // Развитие территорий. - 2020. - № 1(19).-С.23-29.

12. Шпалтаков В.П. Проблемы улучшения инвестиционного климата в России // Вестн. Ом. ун-та. Сер. «Экономика».-2018.- № 1 (61).- С. 56-66. 